\title{
An Examination of the Effects of Contextual Computer-aided Design Exer- cises on Student Modeling Performance
}

\section{Dr. Michael Johnson, Texas A\&M University}

Dr. Xiaobo Peng, Prairie View A\&M University

Associate Professor, Department of Mechanical Engineering, Prairie View A\&M University

\section{Dr. Bugrahan Yalvac, Texas A\&M University}

Bugrahan Yalvac is an associate professor of science and engineering education in the Department of Teaching, Learning, and Culture at Texas A\&M University, College Station. He received his Ph.D. in science education at the Pennsylvania State University in 2005. Prior to his current position, he worked as a learning scientist for the VaNTH Engineering Research Center at Northwestern University for three years. Yalvac's research is in STEM education, 21st century skills, and design and evaluation of learning environments informed by the How People Learn framework.

Mrs. Elif Ozturk

Ms. Ke Liu, Prairie View A\&M University

Ke Liu, is a graduate student and Graduate Research Assistant in the Department of Mechanical Engineering at Prairie View A\&M University. She received her BS in Donghua University, China. Her research interests include CAD, Virtual Reality Technology and CFD. 


\title{
An Examination of the Effects of Contextual Computer-aided Design Exercises on Student Modeling Performance
}

\begin{abstract}
Many in the academe and industry have long found computer-aided design (CAD) education lacking. These critics have decried the lack of strategic skills and the focus on declarative knowledge associated with specific CAD packages. This work will discuss the most recent findings of a three year iterative investigation examining the role of contextual exercises on CAD modeling procedure and the manifestation of adaptive expertise. The effects of a varying number of contextual exercises incorporated in regular instruction throughout a semester will be examined. Contextual exercises consist of students modeling a component that they have a personal connection to, as opposed to a stylized example from the textbook. Modeling performance on a standard assessment is compared for the various groups as is performance on an end of the semester exercise.
\end{abstract}

This work compares the results of student performance on the standard assessment based on whether students received no, one, or four contextual exercises prior to the assessment. Student performance on an end of the semester exercise that is either stylized or contextual in nature is also examined. Student interviews and coding are used to examine the manifestation of adaptive expertise among those various groups. Statistical analyses are used to evaluate differences among the groups.

Interview data showed that there was a slightly greater manifestation of behaviors associated with adaptive expertise in the single contextual self-guided exercise group as compared to those students that used a stylized self-guided exercise. However these differences were of limited statistical significance. The implementation of four contextual exercises showed no increase in the manifestation of adaptive expertise behaviors. In both cases, the implementation of contextual exercises did not result in improved performance on the standard assessment. Limitations of the work and possible causes for some of the unexpected results are detailed.

\section{Introduction}

There has been discussion in the product development community about the model-based enterprise (MBE). The MBE could provide significant opportunities for efficiency and effectiveness in product development ${ }^{1}$. At the core of the MBE are computer-aided design (CAD) models that allow for the more efficient completion of tasks associated with product development. These include computer-aided engineering simulations, computer-aided manufacturing processes and other manipulations of the digital artifacts. CAD models combined with product lifecycle management (PLM) systems have long been proposed as providing great benefits ${ }^{2}$. However, these benefits are predicated on the ability of CAD models to be easily reused and understood by the various actors across the commercialization process. This requires a well-educated technical workforce that can create these models and adapt to an environment with changing tools and thus may require new or adapted skills.

The current paradigms in CAD education are not well aligned with the skills that students will need to be valuable actors in the MBE. There have been complaints about both the lack of adequate $\mathrm{CAD}$ education ${ }^{3}$ as well as complaints from $\mathrm{CAD}$ instructors about the inability of 
professionals to model well in $\mathrm{CAD}^{4}$. Current $\mathrm{CAD}$ instruction is focused on declarative knowledge that is only valuable for performing certain tasks with specific CAD programs ${ }^{3,5}$. Ideally, CAD education would provide more strategic knowledge of the sort that is associated with expertise ${ }^{6}$. This type of strategic knowledge has been shown to be transferable to new or other CAD programs ${ }^{6}$. Ideally, CAD education would promote this type of adaptive expertise.

Expertise is generally categorized as either routine or adaptive ${ }^{7}$. The key differentiating factor between routine and adaptive expertise is that adaptive experts are innovative and efficient, whereas their routine counterparts are only efficient in the domain of their expertise ${ }^{8}$. These adaptive experts are open to inquiry, use their metacognitive and self-regulation skills, and hold more advanced personal epistemologies; this allows adaptive experts to be more flexible, innovative, and creative in novel situations ${ }^{9}$. These are exactly the type of skills that would be valuable in an innovative and dynamic MBE. Fisher and Peterson propose four main dimensions of adaptive expertise: multiple perspective, metacognition, goals and beliefs, and epistemology 10 .

There has been a call to introduce more educational exercises that promote both efficiency and innovation; namely, the type of exercises that would promote adaptive expertise. Contextual exercises have been shown to have a positive impact on students' cognitive and affective domains ${ }^{11}$. Students learn more effectively when they engage in activities that have personal meaning; with respect to CAD education, this may mean modeling objects connected to daily life or personal interest. There is currently a paucity of activities in the curriculum that promote adaptive expertise ${ }^{9}$. There is also a documented lack of opportunity for self-learning in most engineering curricula ${ }^{12}$. This work is part of a larger collaborative research project that examines the role of contextual exercises on development of adaptive expertise. This particular study aims to examine the effects of the introduction of a series of contextual exercises on students' performance in a CAD modeling assessment as well as manifestation of adaptive expertise in an additional modeling exercise. The role of contextual exercise on CAD modeling procedure is also examined. The paper is organized as follows. The methods are introduced in the next section. This is followed by the results from the first two semesters of study. Finally, conclusions, limitations, and future work are detailed.

\section{Methods}

To assess the role of contextual exercises on the manifestation of adaptive expertise and CAD modeling procedures, a series of exercises was introduced into a junior level product design course that uses the laboratory portion of the course for CAD instruction. PTC's Creo Parametric program is used for this purpose. The first step was to establish a baseline level of adaptive expertise through the use of an adaptive expertise survey (AES) instrument. The instrument used in this work was developed by Fisher and Peterson ${ }^{10}$ and uses a 42 question, 6-point Likert-scale to assess adaptive expertise based on four main dimensions: multiple perspective, metacognition, goals and beliefs, and epistemology. This instrument was distributed to the students in the class approximately midway through the semester. A subset of the Fisher and Peterson questions were used to determine dimensional scores through the use of exploratory and confirmatory factor analysis. These analyses used a combination of almost 300 respondents to the survey and included practicing engineers and students at Texas A\&M and Prairie View A\&M Universities. A previous iteration of these analyses is detailed in Ozturk et al. ${ }^{13}$ The original four constructs of 
Fisher and Peterson ${ }^{10}$ were maintained. The questions used for each construct were: multiple perspectives $(5,13,21,25,34,36,39)$; metacognition $(2,6,14,26,30,40)$; goals and beliefs $(3$, $7,38,41)$, and epistemology $(4,8,12,20,33)$.

The contextual exercises were introduced into the course in two semesters in two different manners. Each laboratory meeting in the course is broken into two parts; during the first, the instructor guides students in an activity covering that meeting's content. In the second part of the laboratory, the students are assigned a self-guided exercise to work on independently. There is instructional support available if the students need assistance. The contextual exercises were introduced to replace the stylized examples found in the textbook ${ }^{14}$ that are used for this selfguided part of the laboratory. In one semester a single contextual exercise was added in the middle of the semester. In the other, four contextual exercises were introduced throughout the semester. In each semester, the lecture was broken into three laboratory sections. During both semesters, two sections were assigned contextual exercises (either throughout or in one laboratory meeting) and one section was a control that was assigned the stylized book example for their self-guided exercise. The objects student brought in for the contextual exercises were photographed. Students were provided a ruler to help them determine the dimensions of their object.

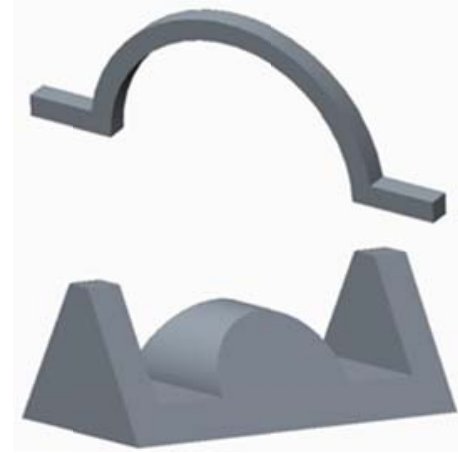

a.

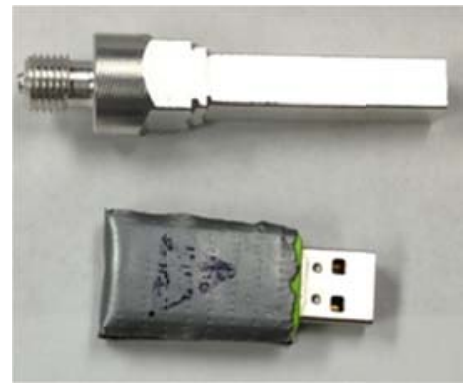

b.

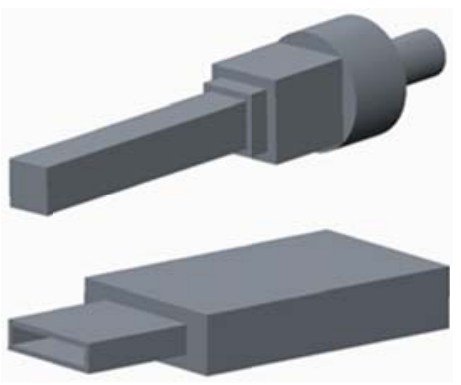

c.

Figure 1. Self-guided Exercises from Lab 2: a. Stylized Exercise Model; b. Photo of Representative Student Contextual Exercise Object; c. CAD Model of Contextual Exercise Object.

During the semester in which the four contextual exercises were introduced, the first was introduced during the second laboratory. The initial lab in the course introduces the software and interface. During the second lab, students learn about basic geometry such as sketches, extrusions, and holes. Students assigned to the contextual exercise sections were asked to bring in two relatively simple objects for the second laboratory. The stylized components that the students model during their self-guided exercise are shown in Figure 1a. A photo of a representative example of the contextual items that student brought in and the corresponding CAD models are shown in Figures $1 \mathrm{~b}$ and $1 \mathrm{c}$, respectively.

The next contextual exercise was introduced during the third laboratory. In this lab, students learn about more complex geometry. This includes an introduction to ancillary features such as rounds and chamfers. Students in the contextual exercise sections were asked to bring in objects 
that contained some of these types of features, but were still relatively simple. The stylized example from the third laboratory is shown in Figure 2a. A photo of a representative contextual object and CAD model are shown in Figures $2 \mathrm{~b}$ and $2 \mathrm{c}$, respectively.

The third contextual exercise was introduced during the fourth laboratory. In this lab meeting, students were introduced to the revolution feature. Students in the contextual sections were asked to bring in an object that had a feature that could be revolved. The stylized example contains a revolved feature, but also builds upon some of the ancillary geometry introduced in laboratory 3 . It is shown in Figure 3a. A photo of a representative contextual object and CAD model are shown in Figures $3 b$ and $3 c$, respectively.

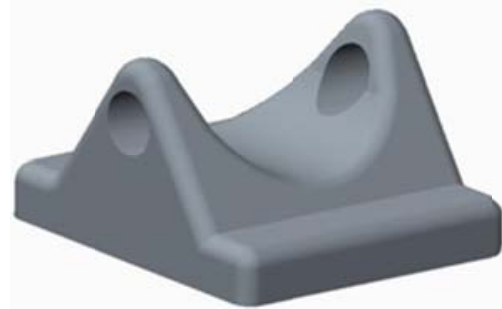

a.

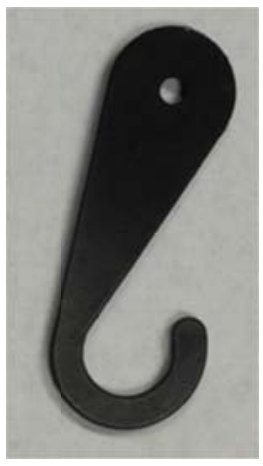

b.

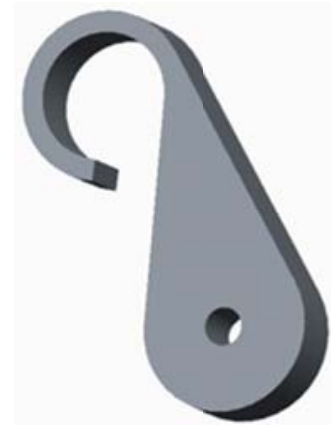

c.

Figure 2. Self-guided Exercises from Lab 3: a. Stylized Exercise Model; b. Photo of Representative Student Contextual Exercise Object; c. CAD Model of Contextual Exercise Object.

The final contextual exercise was introduced in the sixth laboratory session. In this laboratory session, repeating geometry such as patterns and copies is introduced. For the single contextual exercise semester, this represented the only contextual exercise. Students were asked to bring in an item that had some type of repeating geometry. The stylized example is a relatively simple object with a combination of six repeating features; it is shown in Figure 4a. A photo of a representative contextual object and the associated CAD model are shown in Figures $4 \mathrm{~b}$ and $4 \mathrm{c}$, respectively.
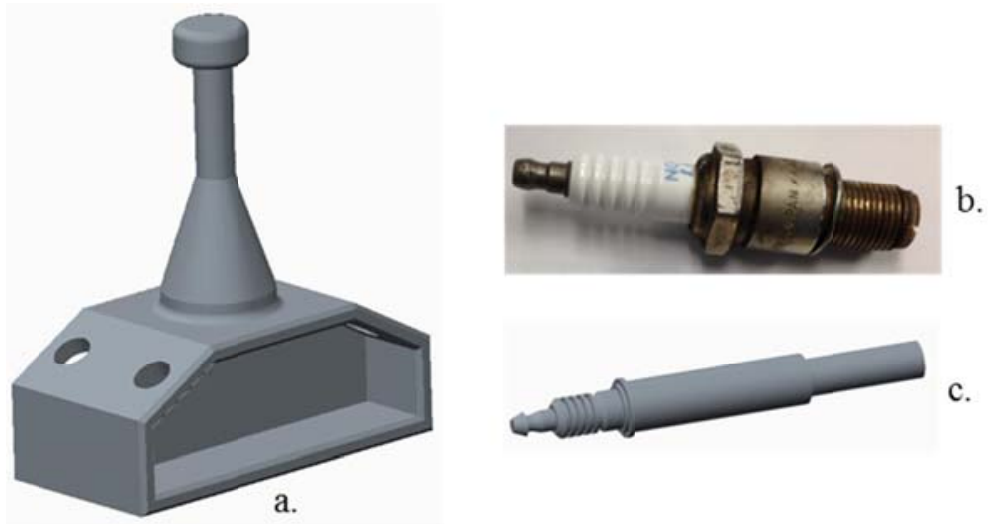

Figure 3. Self-guided Exercises from Lab 4: a. Stylized Exercise Model; b. Photo of Representative Student Contextual Exercise Object; c. CAD Model of Contextual Exercise Object. 


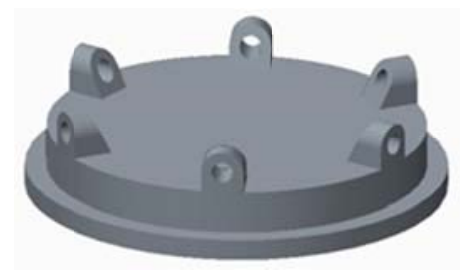

a.

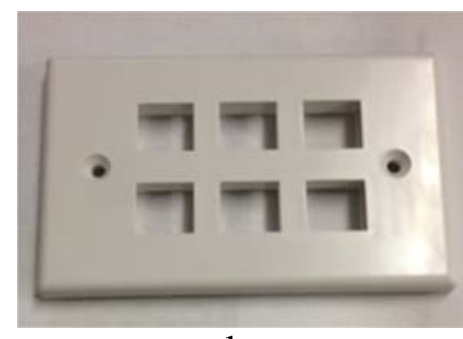

b.

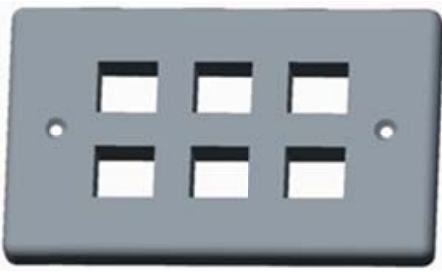

c.

Figure 4. Self-guided exercises from Lab 6: a. Stylized Exercise Model; b. Photo of Representative Student Contextual Exercise Object; c. CAD Model of Contextual Exercise Object.

\section{Lab Practical}

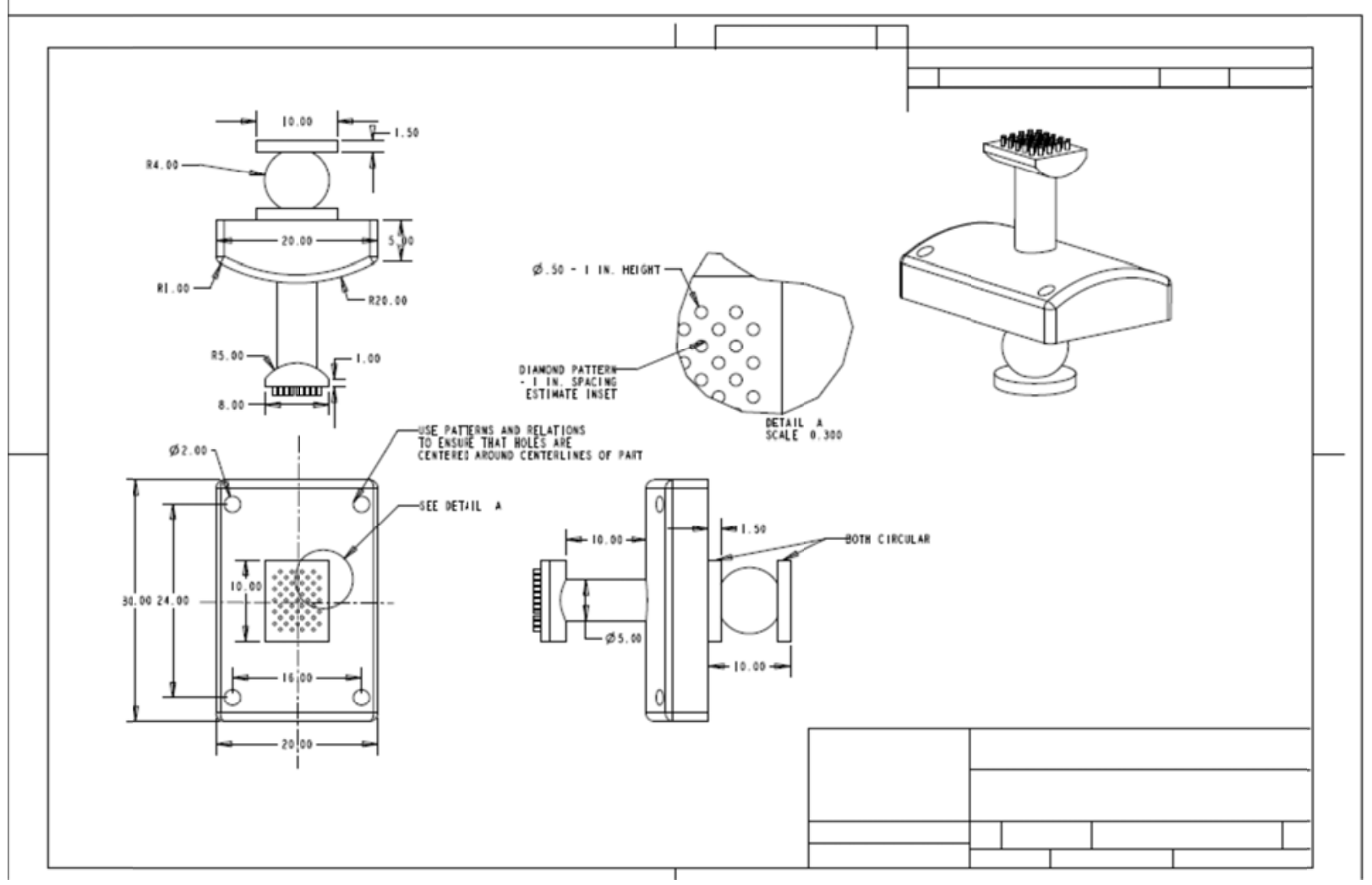

Figure 5. Drawing Distributed to Students for Lab Practical Exercise.

To assess the effect of the contextual exercises on the ability of students to implement their modeling skills, data from the laboratory practical was used during these two semesters. The laboratory practical provides students with a drawing of a component and asks them to create a CAD model of that component. The practical requires students to use the various skills demonstrated in the course to date. The drawing provided to the students for the laboratory practical is shown in Figure 5. The laboratory practical is graded on a 20 point scale based on the various major pieces of geometry (extrusions and revolve features), the creation patterns, and the connection of the features. The laboratory practical is administered after all of the initial 
geometry creation exercises in the course, but prior to students learning about drawings and assemblies.

In both semesters, an additional end of the semester exercise was administered to the students. This exercise again segmented the students into three groups. However, this was not done by section, but by performance on the laboratory practical. Students were either asked to bring in a contextual object (not one they had used previously) of moderate complexity or were provided either a drawing of physical model of stylized component. These are shown in Figure 6. Students were given approximately one hour to model their component. Prior to the modeling exercise students were interviewed about the procedure they planned to use and how they would deal with any challenges that arose. During the exercise, the Camtasia screen capture software was used to record participant screens. After the modeling exercise, students were interviewed again to assess whether their proposed plan was successful, what challenges they encountered, and how confident they were in their modeling.
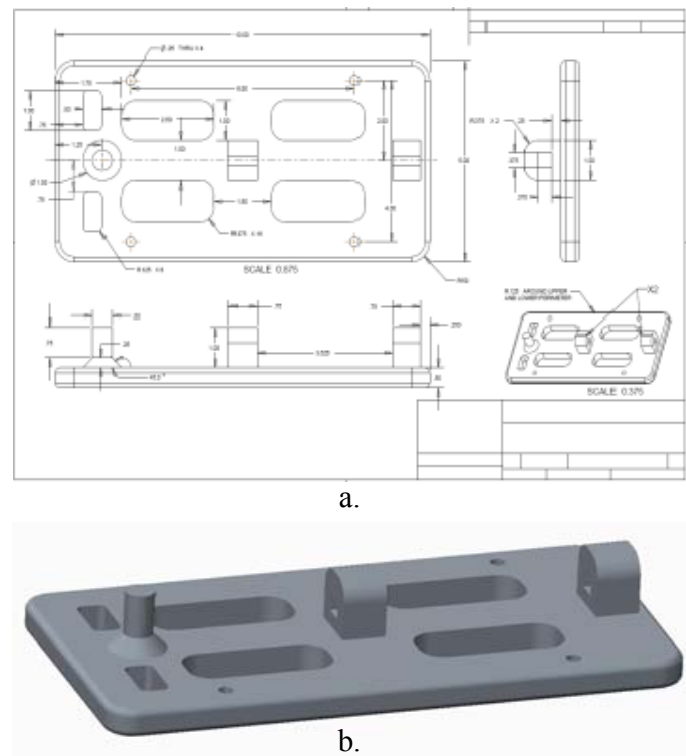

Figure 6. Control item drawing (a.) and screen shot of control CAD model (b.)

The interviews were audio recorded and transcribed verbatim. The constant comparative method was used to analyze the transcripts ${ }^{15,16}$. First open and axial coding was used to analyze the interview responses. Next selective coding was used. The responses were coded along the four dimensions of adaptive expertise defined by Fisher and Peterson ${ }^{10}$. The pre and post interview instances of adaptive expertise were then tabulated. Readers interested in the interview procedure and coding process are referred to Johnson et al. ${ }^{17}$

The Camtasia screen capture videos were used to examine how students used their modeling time. The videos were watched and a time log was tabulated to determine which of five activities a student was engaged in during the exercise. This was only done for the second semester of data collection. These activities included: doing, searching, thinking, trial and error, and regeneration or waiting. Doing time is defined as engaging in productive modeling activities (e.g., creating a feature). Searching time is defined as cursor movement without activity; meaning clicking on 
buttons or menus without carrying out any activity (i.e., unproductively looking for some feature or tool). Thinking time is defined as a lack of cursor movement or panning around the graphic window without purpose. Trial and error is defined as the process encompassing the making of a feature and its subsequent deletion. It should be noted that not all trial and error features are deleted immediately after their creation; in some instances, participants may finish the feature, move on and then come back to delete the feature later. In these cases careful attention is paid to find where in the video analysis the feature was made and where in the video analysis the same feature was deleted. Regeneration or waiting time is the time required for the software to regenerate graphics or complete processes. The percentages of time for each of these categories was then tabulated. Statistical analyses of the tabulated data were used to determine the effect of the two different types of contextual exercises. These are shown in the Results section below.

\section{Results}

In both the single contextual exercise and the multiple contextual exercise groups, data are compared to the two control sections from the data collection semesters. To test for the significance of the results between the two group two sample t-tests are used $(\alpha=0.10)$. These are labeled as the Stylized Exercises group. The Styled Exercises group contained data for 19 useable and complete data sets. These are compared to the Single Contextual Exercise sections in Table 1.

Table 1. Comparison of Single Contextual Exercise to Stylized Exercise Group

\begin{tabular}{|l|c|c|c|c|}
\cline { 2 - 5 } \multicolumn{1}{l|}{} & $\begin{array}{c}\text { Stylized } \\
\text { Exercises }\end{array}$ & $\begin{array}{c}\text { Single } \\
\text { Contextual } \\
\text { Exercise }\end{array}$ & t & $\begin{array}{c}\text { Sig } \\
\text { (2-tailed) }\end{array}$ \\
\hline Number of Students Participating & 19 & 22 & - & - \\
\hline Survey Data & 4.56 & 4.82 & -1.277 & 0.209 \\
\hline Epistemology & 2.86 & 3.18 & -1.106 & 0.276 \\
\hline Goals and Beliefs & 3.39 & 3.60 & -1.094 & 0.281 \\
\hline Multiple Perspectives & 4.62 & 4.29 & 1.647 & 0.108 \\
\hline Metacognition & 13.70 & 15.47 & -1.541 & 0.131 \\
\hline Total Adaptive Expertise & 1.944 & 1.545 & 0.853 & 0.399 \\
\hline Interview Data & 0.611 & 0.545 & 0.273 & 0.786 \\
\hline Pre- Multiple Perspectives & 1.111 & 1.5 & -0.869 & 0.39 \\
\hline Pre- Epistemology & 2.056 & 2.5 & -0.973 & 0.337 \\
\hline Pre- Metacognition & 5.421 & 6.091 & -0.602 & 0.551 \\
\hline Pre- Goals and Beliefs & 0.889 & 0.591 & 1.110 & 0.274 \\
\hline Pre- Total Adaptive Expertise & 0.167 & 0 & 1.524 & 0.136 \\
\hline Post- Multiple Perspectives & 1.056 & 1.409 & -1.055 & 0.298 \\
\hline Post- Epistemology & 1.444 & 1.591 & -0.429 & 0.670 \\
\hline Post- Metacognition & 3.368 & 3.591 & -0.335 & 0.740 \\
\hline Post-Goals and Beliefs & 8.789 & 9.682 & -0.570 & 0.572 \\
\hline Post- Total Adaptive Expertise & 12.42 & 12.14 & 0.185 & 0.854 \\
\hline Interview Total Adaptive Expertise & \multicolumn{5}{|l}{} \\
\hline Assessment Data & \multicolumn{5}{|l}{} \\
\hline Lab Practical Score & \multicolumn{5}{|l}{} \\
\hline
\end{tabular}


The data from the initial survey is shown in Table 1. In the case of the single contextual exercise, the survey was administered prior to the one contextual exercise and thus should not show statistically significant differences between the groups. While the total adaptive expertise in the survey is greater for the single contextual exercise group, it is not statistically significant. With respect to the interview data, it would be expected that if contextual exercises promoted the manifestation of adaptive expertise, the interview responses would show a higher level of instances related to adaptive expertise for the contextual group than the control group using stylized examples. This would be especially true given that the baseline adaptive expertise (from the AES) was higher for the contextual group. While the pre-interview data for Metacognition and Goals and Beliefs showed more manifestations of adaptive expertise for the contextual group, these results were not statistically significant. The pre-interview data for Multiple Perspectives and Epistemology were actually higher for the control group, however these results were again not statistically significant. The overall pre-interview manifestations of adaptive expertise were slightly greater for the control group, but again this difference was not statistically significant.

In the case of post-interview data, the results for Multiple Perspectives and Epistemology were again higher for the control group than for that of the group that participated in the one contextual exercise. These results were not statistically significant. The post-interview data for the Metacognition and Goals and Beliefs dimensions were higher for the single contextual exercise group. Again, these results were not statistically significant. The overall post-interview data and the total interview manifestations of adaptive expertise were higher for the single contextual exercise group than the control group, but these results were not statistically significant. Finally, the performance on the laboratory practical was not significantly different for the contextual exercise group; in fact, the control group using stylized exercises performed better.

Next, the group consisting of the two sections that had four contextual exercises throughout the semester was compared to the two control sections that used stylized self-guided exercises.

These results are shown in Table 2. The stylized group consisted again of 19 participants while the contextual group consisted of 22 participants. In this case, the survey was administered after some of the initial contextual exercises in the laboratory portion of the course. This may have affected the survey responses. Students in the four contextual exercise group had higher adaptive expertise scores on the dimensions of Epistemology, Goals and Beliefs, and Multiple Perspectives. In the cases of Goals and Beliefs and Multiple Perspectives, these differences were statistically significant. The overall adaptive expertise score from the survey was also statistically significantly higher for the four contextual exercise group.

The pre-interview manifestations for the four contextual exercise group was higher than that of the control stylized self-guided exercise group along the dimensions of Epistemology, Metacognition, and Goals and Beliefs. However, none of these differences were statistically significant. The manifestation of adaptive expertise on the Multiple Perspectives dimension was higher in the stylized exercise group; this difference was statistically significant. The total preinterview manifestations of adaptive expertise between the groups were practically equal. In the post-interview manifestations of adaptive expertise, instance for the stylized example group were higher along the dimensions of Multiple Perspectives, Epistemology, and Metacognition. In the 
case of Metacognition, this difference was statistically significant. The overall post-interview total number of manifestations of behavior associated with adaptive expertise were slightly higher for the stylized exercise group than the contextual exercise group. This was also the case for the total interview data. Neither of these two differences was statistically significant.

Table 2. Comparison of Four Contextual Exercises to Stylized Exercise Group

\begin{tabular}{|c|c|c|c|c|}
\hline & $\begin{array}{l}\text { Stylized } \\
\text { Exercises }\end{array}$ & $\begin{array}{c}\text { Four } \\
\text { Contextual } \\
\text { Exercise }\end{array}$ & $\mathrm{t}$ & $\begin{array}{c}\text { Sig } \\
\text { (2-tailed) }\end{array}$ \\
\hline Number of Students participating & 19 & 22 & - & - \\
\hline \multicolumn{5}{|l|}{ Survey Data } \\
\hline Epistemology & 4.56 & 4.63 & -0.315 & 0.754 \\
\hline Goals and Beliefs & 2.86 & 3.33 & -1.717 & 0.094 \\
\hline Multiple Perspectives & 3.39 & 3.73 & -1.854 & 0.071 \\
\hline Metacognition & 4.62 & 4.43 & 0.917 & 0.365 \\
\hline Total Adaptive Expertise & 13.70 & 16.12 & -2.476 & 0.018 \\
\hline \multicolumn{5}{|l|}{ Interview Data } \\
\hline Pre- Multiple Perspectives & 1.94 & 1.10 & 2.173 & 0.036 \\
\hline Pre- Epistemology & 0.61 & 1.10 & -1.350 & 0.185 \\
\hline Pre- Metacognition & 1.11 & 1.19 & -0.219 & 0.828 \\
\hline Pre- Goals and Beliefs & 2.06 & 2.38 & -0.681 & 0.500 \\
\hline Pre- Total Adaptive Expertise & 5.42 & 5.50 & -0.078 & 0.938 \\
\hline Post- Multiple Perspectives & 0.89 & 0.86 & 0.113 & 0.911 \\
\hline Post- Epistemology & 0.17 & 0.00 & 1.488 & 0.145 \\
\hline Post- Metacognition & 1.06 & 0.57 & 1.951 & 0.059 \\
\hline Post-Goals and Beliefs & 1.44 & 1.48 & -0.104 & 0.918 \\
\hline Post- Total Adaptive Expertise & 3.37 & 2.77 & 0.982 & 0.332 \\
\hline Interview Total Adaptive Expertise & 8.79 & 8.27 & 0.360 & 0.721 \\
\hline \multicolumn{5}{|c|}{ Procedure Data ( $N=10$ for Stylized and $N=12$ for Contextual) } \\
\hline Percent Doing & $36.6 \%$ & $40.2 \%$ & -0.534 & 0.599 \\
\hline Percent Searching & $4.4 \%$ & $2.6 \%$ & 0.954 & 0.351 \\
\hline Percent Thinking & $35.8 \%$ & $29.7 \%$ & 1.703 & 0.103 \\
\hline Percent Trial and Error & $19.5 \%$ & $27.0 \%$ & -0.993 & 0.332 \\
\hline Percent Waiting & $3.7 \%$ & $0.5 \%$ & 1.928 & 0.068 \\
\hline \multicolumn{5}{|l|}{ Assessment Data } \\
\hline Lab Practical Score & 12.42 & 10.73 & 1.021 & 0.314 \\
\hline
\end{tabular}

Next the video capture data were used to analyze the way that participants spent their modeling time. The time spent Doing and for Trial and Error was slightly greater for the contextual exercise group, the time spent Searching and Thinking was higher for the stylized exercise group. None of these differences was statistically significant. The time spent Waiting was higher for the stylized exercise group, but this was due to specific participants and is probably not practically relevant. These results are somewhat unexpected. It has been noted that experts spend more time planning and doing ${ }^{18}$, while trial and error is used by those with limited skill ${ }^{19}$. The results shown here are the opposite of what would be expected if the contextual exercises were 
promoting adaptive expertise among that group. However these results are in agreement with the laboratory practical scores, which were higher for the stylized exercise group. However, this difference was not statistically significant.

\section{Discussion}

Conclusions

This work presented the initial findings from an investigation of the role of contextual exercises on the manifestation of adaptive expertise in CAD. Also investigated were the role of these types of exercises on a general CAD skill assessment and modeling procedure. This work examined the implementation of two forms of contextual exercises. In one case a single contextual exercise was introduced and in the other, four contextual exercises were introduced. The manifestation of adaptive expertise from coded interview transcriptions were used to examine the differences between these contextual exercise groups and a control group that used a stylized book exercise. Screen capture data were used to examine the way in which participants used their modeling time; a modeling exercise was also used to assess general modeling skill.

Preliminary results showed that there was a slightly higher manifestation of adaptive expertise (measured by tabulated instances) in the single contextual exercise group than the control stylized exercise group. This was true in both the pre and post interview tabulation of instances. However, none of the pre, post, or total differences were statistically significant. None of the main dimensions of adaptive expertise in this group were statistically significant either. For the four contextual exercise group, the pre-interview manifestations of adaptive expertise were higher than for the control stylized exercise group, but the post-interview and overall number of manifestations was higher for the stylized exercise group. These overall differences were not statistically significant. The pre-interview instances for Multiple Perspectives and the postinterview instance of Metacognition were statistically significantly greater for the stylized exercise group. Time usage data for the two groups showed slightly more Thinking time for the stylized exercise group and slightly more Trial and Error for the four contextual exercise group. This was unexpected, given that Trial and Error is usually associated with those that have less expertise ${ }^{19}$. However, this was in agreement with the results from the laboratory practicals.

\section{Limitations and Future Work}

These preliminary conclusions should be examined in light of some limitations associated with the current work. The most significant of these is the aggregated nature of the data from the end of semester exercise that was used to elicit the interview and time usage data. While compared along the contextual and stylized self-guided exercise dimensions, these two groups also contain different types of end of semester modeling exercises. In some cases, students were engaging in another contextual modeling exercises whereas in others they were modeling from either a drawing or a 3-D model of a stylized part. These data were not broken down by these categories. Future work will further analyze these data along the type of exercise. It should also be noted that the data presented in this work covers two semesters from one university. Additional data will be collected to allow for a more robust analysis of the findings. Finally, one of the key unexpected findings was the lack of a statistically significant difference (or slightly poor performance) from those students engaged in the contextual exercise on the laboratory practical. However, the laboratory practical is more stylized than contextual in nature and may not be the 
best way to evaluate the modeling skills associated with adaptive expertise. Future work will attempt to better capture these skills.

\section{Acknowledgement}

This material is supported by the National Science Foundation under EEC Grant Numbers 1129403 and 1129411. Any opinions, findings, conclusions, or recommendations presented are those of the authors and do not necessarily reflect the views of the National Science Foundation.

\section{References}

[1] Frechette, S.P., (2011). Model based enterprise for manufacturing. 44th CIRP International Conference on Manufacturing Systems. Madison, WI.

[2] Liu, D.T. \& Xu, X.W., (2001). A review of web-based product data management systems. Computers in Industry, 44 (3), 251-262.

[3] Ye, Z., Peng, W., Chen, Z. \& Cai, Y.-Y., (2004). Today's students, tomorrow's engineers: An industrial perspective on cad education. Computer-Aided Design, 36 (14), 1451-1460.

[4] Salehi, V.\& Mcmahon, C., (Year). Action research into the use of parametric associative cad systems in an industrial context. In: Norell Bergendahl, M., Grimheden, M., Leifer, L., Skogstad, P. \& Lindemann, U., ed.^eds. Proceedings of the 17th International Conference on Engineering Design (ICED'09), Vol. 5, Stanford, CA, USA, 133-144.

[5] Hamade, R.F., Artail, H.A. \& Jaber, M.Y., (2007). Evaluating the learning process of mechanical cad students. Computers \& Education, 49 (3), 640-661.

[6] Lang, G.T., Eberts, R.E., Gabel, M.G. \& Barash, M.M., (1991). Extracting and using procedural knowledge in a cad task. IEEE Transactions on Engineering Management, 38 (3), 257-268.

[7] Hatano, G. \& Inagaki, K., (1986). Two courses of expertise. In Stevenson, H.W., Azuma, H. \& Hakuta, K. eds. Child development and education in japan. New York: W.H. Freeman, 262-272.

[8] Schwartz, D.L., Bransford, J.D. \& Sears, D., (2005). Efficiency and innovation in transfer. In Mestre, J.P. ed. Transfer of learning from a modern multidisciplinary perspective. Greenwich, CT :: IAP.

[9] Hatano, G. \& Oura, Y., (2003). Commentary: Reconceptualizing school learning using insight from expertise research. Educational Researcher, 32 (8), 26-29.

[10] Fisher, F.T. \& Peterson, P.L., (Year). A tool to measure adaptive expertise in biomedical engineering studentsed.^eds. 2001 ASEE Annual Conference and Exposition:, Albuquerque, NM: ASEE, 1249-1263.

[11] Bransford, J., Brown, A.L., Cocking, R.R. \& National Research Council (U.S.). Committee on Developments in the Science of Learning., (1999). How people learn : Brain, mind, experience, and school Washington, D.C.: National Academy Press.

[12] Harris, M. \& Cullen, R., (2009). A model for curricular revision: The case of engineering. Innovative Higher Education, 34 (1), 51-63.

[13] Ozturk, E., Yalvac, B., Peng, X., Valverde, L.M., Mcgary, P. \& Johnson, M.D., (2013). Analysis of contextual computer-aided design exercises. ASEE Annual Conference and Exposition, Conference Proceedings. Atlanta, GA, 2013-6506.

[14] Toogood, R. \& Zecher, Z., (2011). Creo parametric 1.0 tutorial and multimedia cd Mission, KS: SDC Publications. 
[15] Creswell, J.W., (2007). Qualitative inquiry and research design: Choosing among five approaches Thousand Oaks, CA: SAGE Publications.

[16] Glaser, B.G. \& Strauss, A.L., (1967). The discovery of grounded theory: Strategies for qualitative research: Aldine de Gruyter.

[17] Johnson, M.D., Ozturk, E., Valverde, L., Yalvac, B. \& Peng, X., (2013). Examining the role of contextual exercises and adaptive expertise on cad model creation procedures. In Kurosu, M. ed. Human-Computer Interaction Part II. Berlin: Springer-Verlag, 408-417.

[18] Atman, C.J., Adams, R.S., Cardella, M.E., Turns, J., Mosborg, S. \& Saleem, J., (2007). Engineering design processes: A comparison of students and expert practitioners. Journal of Engineering Education, 96 (4), 359-379.

[19] Bhavnani, S.K., James H. Garrett, J. \& Shaw, D.S., (Year). Leading indicators of cad experienceed.^eds. Proceedings of the fifth international conference on Computer-aided architectural design futures, Pittsburgh, Pennsylvania, United States: North-Holland Publishing Co., 313-334. 